\title{
Interference fit effect on holed single plates loaded with tension-tension stresses
}

\author{
D. Croccolo \\ DIEM, University of Bologna, Bologna (Italy) \\ dario.croccolo@unibo.it \\ M. De Agostinis \\ DIEM, University of Bologna, Bologna (Italy) \\ m.deagostinis@unibo.it \\ N. Vincenzi \\ DIEM, University of Bologna, Bologna (Italy) \\ nicolo.vincenzi@unibo.it
}

\begin{abstract}
This paper deals with the influence of interference fit coupling on the fatigue strength of holed plates. The effect was investigated both experimentally and numerically. Axial fatigue tests have been carried out on holed specimens made of high performance steel $1075 \mathrm{MPa}$ of Ultimate strength and 990MPa of Yield strength) with or without a pin, made of the same material, press fitted into their central hole. Three different conditions have been investigated: free hole specimens, specimens with $0.6 \%$ of nominal specific interference and specimens with $2 \%$ of nominal specific interference. The experimental stress-life $(\mathrm{S}-\mathrm{N})$ curves pointed out an increased fatigue life of the interference fit specimens compared with the free hole ones. The numerical investigation was performed in order to analyse the stress fields by applying an elastic plastic 2D simulation with a commercial Finite Element software. The stress history and distribution along the contact interference of the fitted samples indicates a significant reduction of the local stress range due to the externally applied loading (remote stress) since a residual and compressive stress field is generated by the pin insertion.
\end{abstract}

SOMMARIO. In questo lavoro è stata analizzata l'influenza di un accoppiamento per interferenza sulla resistenza a fatica di piastre forate. L'effetto è stato studiato sia sperimentalmente sia numericamente. Le prove di fatica sono state condotte su provini forati in acciaio ad alte prestazioni $(1075 \mathrm{MPa}$ di sollecitazione massima e $990 \mathrm{MPa}$ di snervamento) con o senza un perno dello stesso materiale, inserito per interferenza nel foro centrale. Tre diverse condizioni dei provini sono state studiate: provini con foro libero, provini con $0,6 \%$ d'interferenza specifica nominale generata dal perno e provini con $2 \%$ di interferenza specifica nominale generata dal perno. La curva di vita a fatica $(\mathrm{S}-\mathrm{N})$ ottenuta ha evidenziato un'influenza positiva dell'interferenza sulla resistenza a fatica dei provini. L'indagine numerica è stata realizzata al fine di calcolare lo stato di deformazione e sollecitazione in campo elasto-plastico su una geometria semplificata $2 \mathrm{D}$ del provino in esame; allo scopo è stato impiegato un software commerciale agli elementi finiti. La storia di carico e la distribuzione delle sollecitazioni intorno al foro generato sia dall'interferenza sia dal carico esterno applicato, mostra una significativa riduzione dell'ampiezza della sollecitazione locale nel caso di interferenza dovuta alla presenza di tensioni residue di compressione.

KEYWORDS. Fatigue; Interference-fit; Holed single plate. 


\section{INTRODUCTION}

$\mathrm{F}$

ailure of mechanical components is mainly caused by the fatigue stresses especially in the presence of geometric discontinuities such as the holes machined in order to join two different parts through, for instance, bolts or pins [1]. In the case of bolted connections the holes have, normally, a clearance coupling with the shank of bolts because the connection leverages the friction forces generated between the mating parts [2]. On the other hand the pins connections (shaft-hub connections) can be realised with different amount of interference [3-5]. The holes cause a geometrical discontinuity, which leads to stress concentration during the loading; furthermore, the drilling operation creates rough surfaces or damages so that the fatigue life of the component may be drastically reduced. Such situation forces a compensation of the fatigue life reduction that can be obtained with different techniques such as the cold expansion [6,7] or the interference fit connections. The present paper aims at investigating the effect of the interference fit level on the fatigue life of holed plates, which can be used in riveted connections schematically sketched in Fig. 1. Since some catastrophic failures may occur in this type of joints, it was decided to investigate the relation between the amount of interference and the fatigue life. There are a lot of studies concerning the effect of interference fit on the fatigue life [812]; however, these papers are mainly devoted to the study of aluminium alloys (2xxx and $7 \mathrm{xxx}$ series) or the direct effect of interference fit is shadowed by either cold expansion or bolt clamping effect. On the opposite the material investigated in this paper is high strength steel so that no previous tests or results can be found concerning this application.
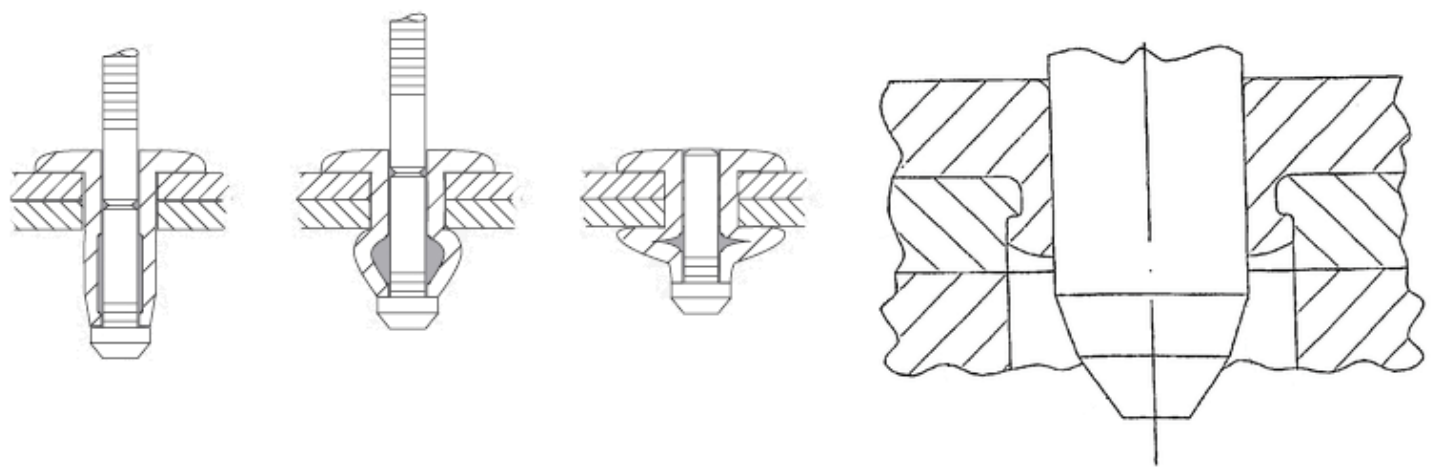

Figure 1: Example of rivet connection.

\section{EXPERIMENTAL METHODS AND TOOLS}

T he specimens are reported in the draft of Fig. 2. They were machined in order to obtain the actual dimension $(160 \mathrm{~mm}$ high, $18 \mathrm{~mm}$ width and $4 \mathrm{~mm}$ of thickness with a hole diameter $\mathrm{D}=5 \mathrm{~mm})$.

The material properties are the following: Ultimate stress 1075MPa, Yield point 990MPa, Young's modulus $209 \mathrm{GPa}$, slope of the plastic curve $578 \mathrm{MPa}$, Poisson's ratio 0.3 , density $7.850 \mathrm{~kg} / \mathrm{m}^{3}$. In order to analyse the interference effect on the fatigue strength, some pins made of the same material have been machined. Two different pin diameters were investigated: $\mathrm{d}=5.03 \mathrm{~mm}$ and $\mathrm{d}=5.1 \mathrm{~mm}$ in order to obtain a specific interference of $0.6 \%$ (low level) and $2 \%$ (high level), respectively, the specific interference being calculated as $I \%=(d-D) / D$.

A set of 7 specimens has been tested for each of the three different conditions: i) open hole $(O H)$, ii) low interference level (IOG) and iii) high interference level (I2). An additional specimen has been used for the I2 level in order to find the run out point. Therefore a total of 22 specimens have been machined and tested. The testing machine was an hydraulic press with a load cell of $100 \mathrm{kN}$ (frequency up to $25 \mathrm{~Hz}$ ) manufactured by Giuliani s.r.l.. The pins have been press fitted into the plates by the same standing press while standard clamps provided by the press manufacturer have been used to lock the specimens; the pin insertion, the specimen lock system and an example of fracture surface are shown in Fig. 3a, $3 \mathrm{~b}$ and $3 \mathrm{c}$ respectively. The white circle of Fig $3 \mathrm{c}$ indicates the starting point of the crack.

The maximum remote stresses $(R S=F / A)$ were set in the range of $725 \mathrm{MPa}$ and $200 \mathrm{MPa}$ : such nominal stresses have been calculated as the ratio between the external force applied by the standing press and the specimen gross section $\mathrm{A}=18 * 4=72 \mathrm{~mm}^{2}$. The $\mathrm{OH}$ specimens have been tested with steps of $75 \mathrm{MPa}$ from $650 \mathrm{MPa}$ to $200 \mathrm{MPa}$ whereas the IXX specimens have been tested with steps of $37.5 \mathrm{MPa}$ (from $650 \mathrm{MPa}$ to $425 \mathrm{MPa}$ for 106 specimens and from $725 \mathrm{MPa}$ to $500 \mathrm{MPa}$ plus a single point at $425 \mathrm{MPa}$ for $I 2$ specimens). The stress ratio for all the specimens was taken equal to $\mathrm{R}=0.1$. 

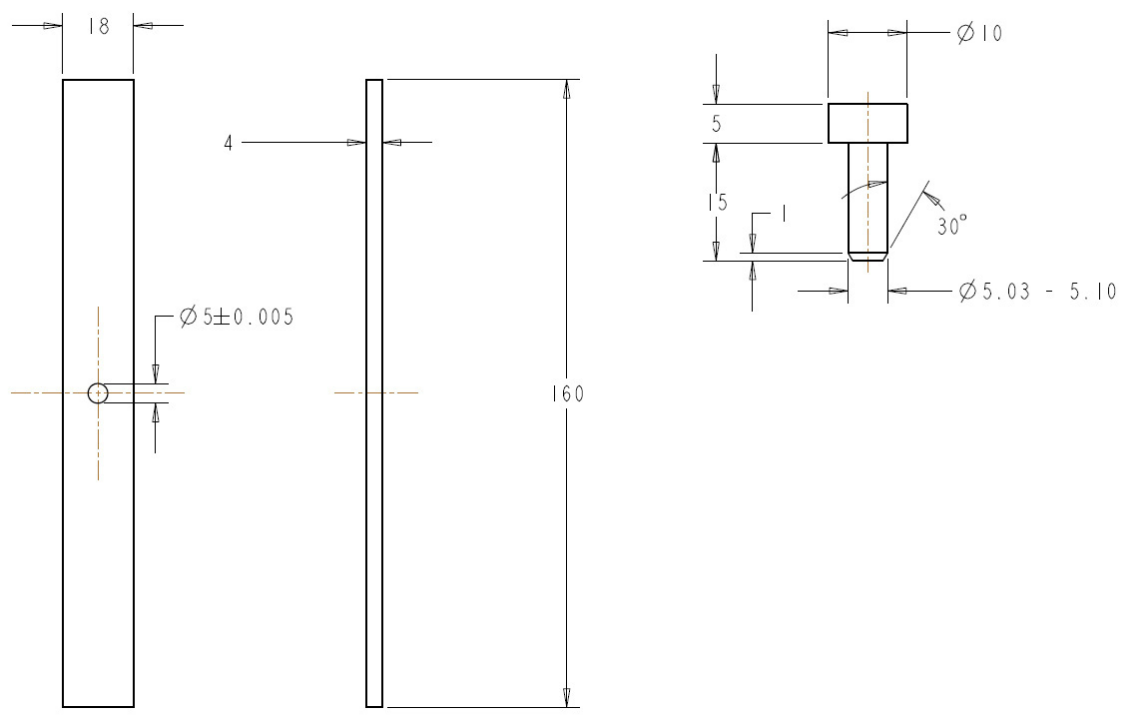

Figure 2: Specimen draft: $K_{t}=3.31$.

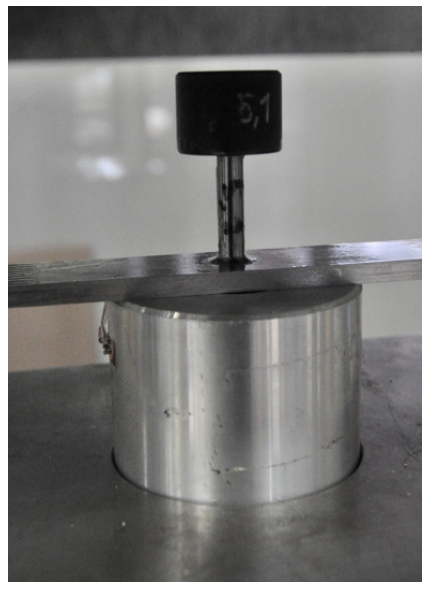

a)

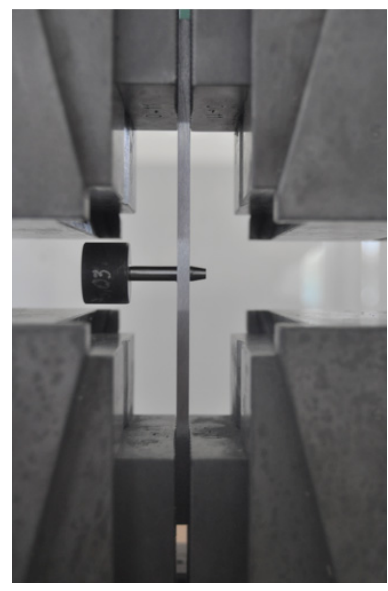

b)

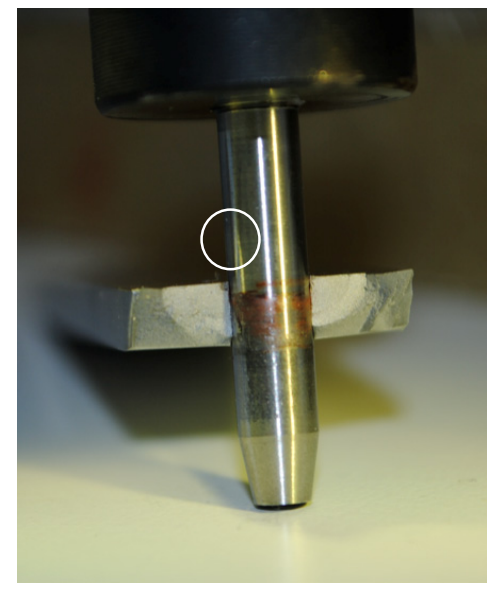

c)

Figure 3: Pin insertion, specimen lock system and fracture surface.

\section{'Tests' Results}

he test plan and results are reported in Tab. 1, 2 and 3 for $O H, I O 6$ and $I 2$ respectively, whereas the corresponding $S-N$ curves are reported in Fig. 4.

\begin{tabular}{llllllll}
\hline Open Hole & Point \# 1 & Point \# 2 & Point \# 3 & Point \# 4 & Point \# 5 & Point \# 6 & Point \# 7 \\
$\begin{array}{l}\text { External load (kN) } \\
\begin{array}{l}\text { Remote maximum } \\
\text { stress (MPa) }\end{array}\end{array}$ & 46.8 & 41.4 & 36 & 30.6 & 25.2 & 19.8 & 14.4 \\
\begin{tabular}{l} 
Cycles \\
\hline
\end{tabular} & 5,89 & 500 & 425 & 350 & 275 & 200 \\
\end{tabular}

Table 1: Stress results for the $O H$ specimens. 


\begin{tabular}{lccccccc}
\hline I06 & Point \# 1 & Point \# 2 & Point \# 3 & Point \# 4 & Point \# 5 & Point \# 6 & Point \# 7 \\
External load (kN) & 46.8 & 44.1 & 41.4 & 38.7 & 36 & 33.3 & 30.6 \\
$\begin{array}{l}\text { Remote maximum } \\
\text { stress (MPa) }\end{array}$ & 650 & 612.5 & 575 & 537.5 & 500 & 462.5 & 425 \\
Cycles & 11,710 & 98,239 & 136,289 & 232,356 & 684,844 & 692,557 & $1,347,271$ \\
\hline
\end{tabular}

Table 2: Stress results for the $I 06$ specimens.

I2

\begin{tabular}{lcccccccc} 
External load (kN) & 52.2 & 49.5 & 46.8 & 44.1 & 41.4 & 38.7 & 36 & 30.6 \\
$\begin{array}{l}\text { Remote maximum } \\
\text { stress (MPa) }\end{array}$ & 725 & 687.5 & 650 & 612.5 & 575 & 537.5 & 500 & 425 \\
$\begin{array}{l}\text { Cycles } \\
\text { 35,260 }\end{array}$ & 70,017 & 112,800 & 136,490 & 193,510 & 300,535 & $430,877 \begin{array}{c}2,000,000 \\
\text { (run out) }\end{array}$ \\
\hline
\end{tabular}

Table 3: Stress results for the $I 2$ specimens.

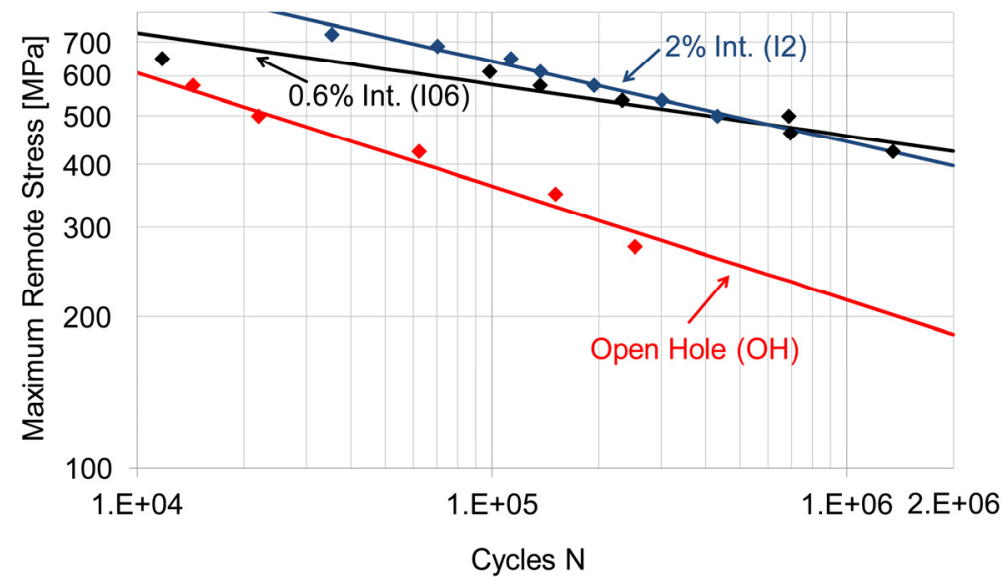

Figure 4: S-N Diagram.

\section{Discussion}

$\mathrm{B}$ y focusing attention on the $S-N$ diagram reported in Fig. 4, it is possible to confirm that the interference fit level has a strong and positive influence on the fatigue strength of the $\mathrm{OH}$ specimen, as widely demonstrated in $[5,7]$. However, a remarkable difference can be noticed between the two levels, IO6 and I2: the higher is the interference level, the higher is the fatigue strength at the highest levels of remote stress. Conversely, by reducing the remote stress, the fatigue strength and the Endurance Limit is quite the same for different interference levels. This experimental evidence can be explained by advocating the actual amplitude of the local stress field in the vicinity of the hole. The observed cracking behaviour indicates a crack initiation close to the cross section of the holed surface (see Fig. 3), so that, it is clear that the actual amplitude of axial stress, normal to the cross section of the specimen, is the driving force of the crack propagation. The amplitude depends on both the remote stress and the local residual (compressive) stresses due to overcoming of the Yielding point. For this reason the local amplitude, depending on both the remote stress and the interference level, has been calculated and analysed. A number of Finite Element Analyses (FEA) have been carried out in order to confirm what stated above by directly following the method proposed by $[6,7,13]$. In Fig. 5 an example of the FEA model (mesh and contour plot of results) is reported. The analyses are conducted on a $2 \mathrm{D}$ elastic-plastic plane stress model (6 nodes triangular elements), in which three different steps have been simulated: i) the interference (if present), ii) the application of the maximum remote stress and iii) the unloading with $\mathrm{R}=0.1$. The actual stress amplitude along the cross section of the specimens, which can be related to fatigue life, has been calculated as the difference between the axial stresses of the phases ii) and iii) and reported in Fig. 6a, $6 \mathrm{~b}$ and $6 \mathrm{c}$ for the $\mathrm{OH}, I 06$ and $I 2$ specimens respectively: the 
diagrams refer to a remote stress of $R S=357.5 \pm 292.5$ (black curves) and to a remote stress of $R S=233.75 \pm 191.25$ (gray curves) which correspond to a high and low fatigue remote stress respectively.

The diagrams of Fig. 6 point out a significant discrepancy among the three actual stress ranges, especially when they are calculated close to the hole; the $O H$ specimen exhibits a stress range of about $1,800 \mathrm{MPa}$, the $I 06$ exhibits a stress range of about $1,050 \mathrm{MPa}$ and $I 2$ exhibits a stress range of about $800 \mathrm{MPa}$ when $R S=357.5 \pm 292.5 \mathrm{MPa}$ (black curves of Fig. 6). If the remote stress decreases the discrepancies among actual ranges change: the $\mathrm{OH}$ range remains greater than $I 06$ and $I 2$ ones, but the $I 06$ and $I 2$ ranges tend to become equal. Indeed when $R S=233.75 \pm 191.25 \mathrm{MPa}$ (gray curves of Fig. 6) the $\mathrm{OH}$ specimen exhibits a stress range of about $1,200 \mathrm{MPa}$ whereas the $I 06$ and the $I 2$ specimens exhibit the same stress range of about $400 \mathrm{MPa}$. This is the reason why the fatigue strength of $I 06$ and $I 2$ specimens tends to be the same when the remote stress decreases. This occurrence is well indicated in Fig. 7 where the stress ranges are plotted as a function of the specific interference for different remote stresses: in the diagram of Fig. $6 \mathrm{~b}$ the stress range at $I 06$ and at $I 2$ is, again, the same so that the fatigue strength should be similar; this event is also confirmed by the S-N diagram of Fig. 4 in which at $425 \mathrm{MPa}$ of maximum remote stress the number of cycles reached by $I 06$ and by $I 2$ specimens is quite the same. The diagrams of Fig. 7 are also useful to indicate the minimum interference level sufficient to improve the fatigue strength for a stated remote stress; for instance, in the case of $357.5 \pm 292.5 \mathrm{MPa}$ of remote stress an interference level of $0.6 \%$ is high enough for increasing the fatigue strength, whereas for $357.5 \pm 292.5 \mathrm{MPa}$ of remote stress an interference level of about $1 \%$ is suggested.
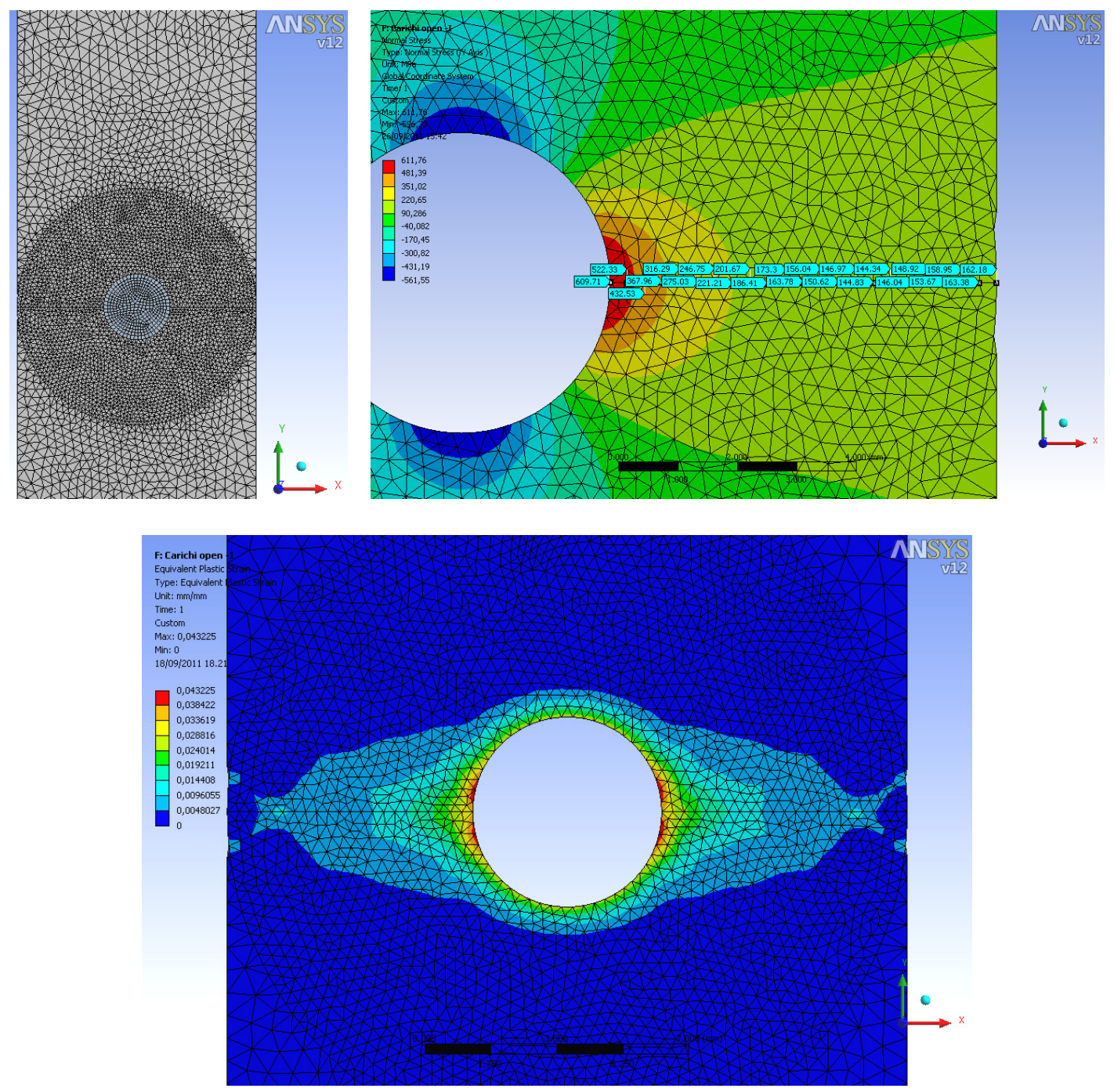

Figure 5: FEA Model. 


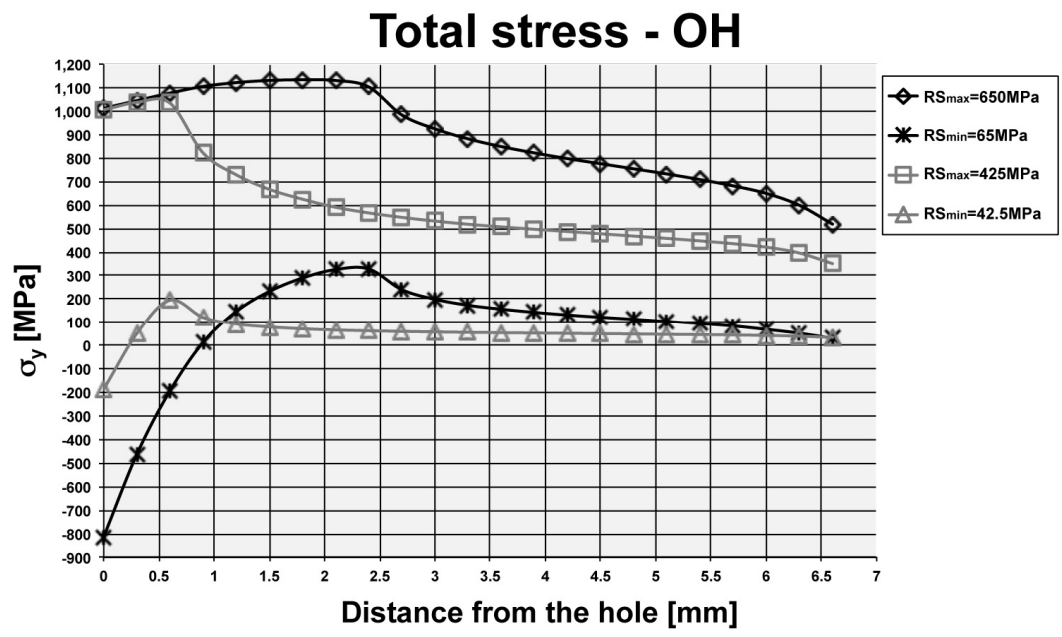

(a)
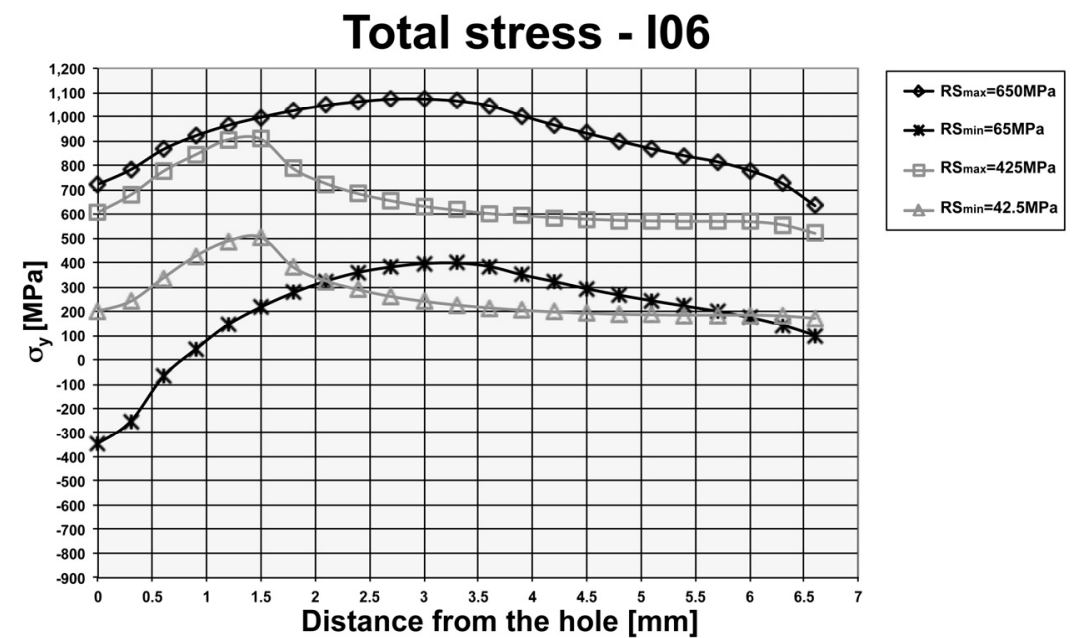

(b)

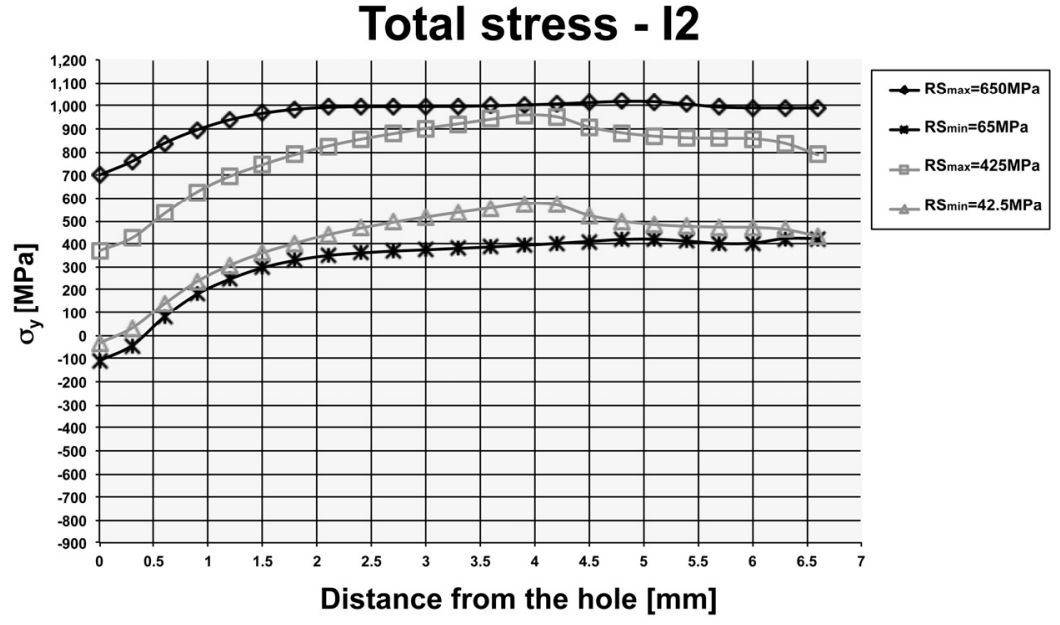

(c)

Figure 6: Axial stress amplitude diagrams (Total stress amplitude: a) OH; b) I06; c) I2). 


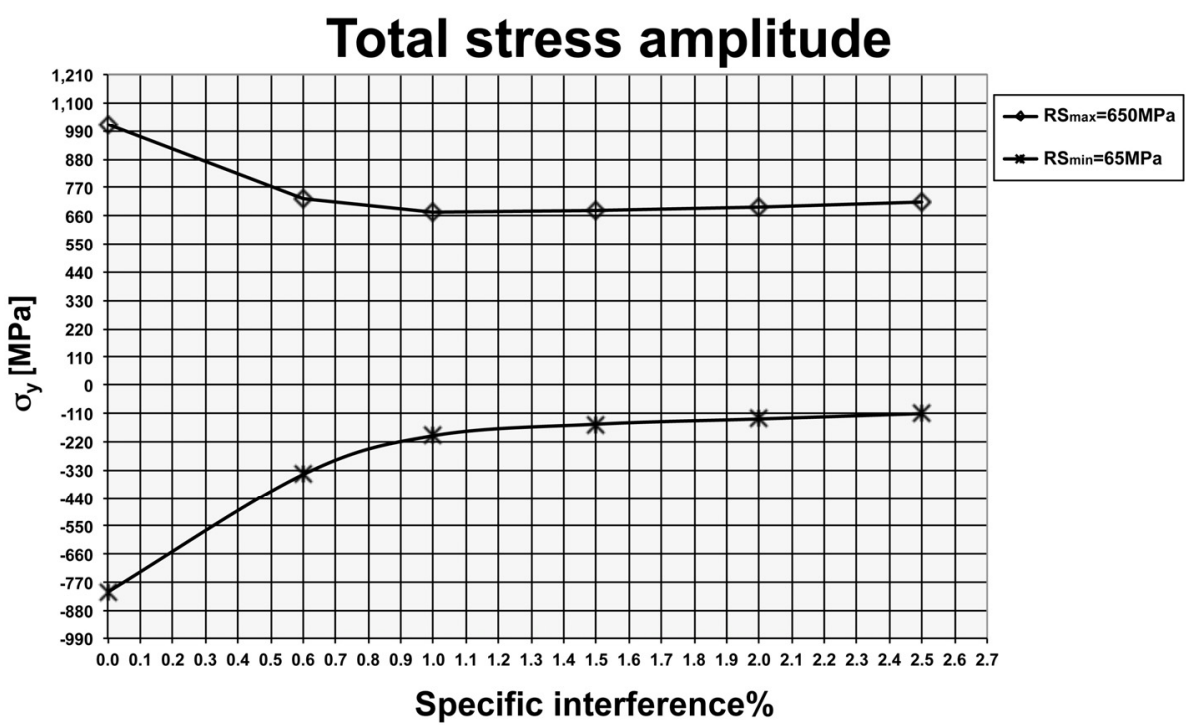

(a)

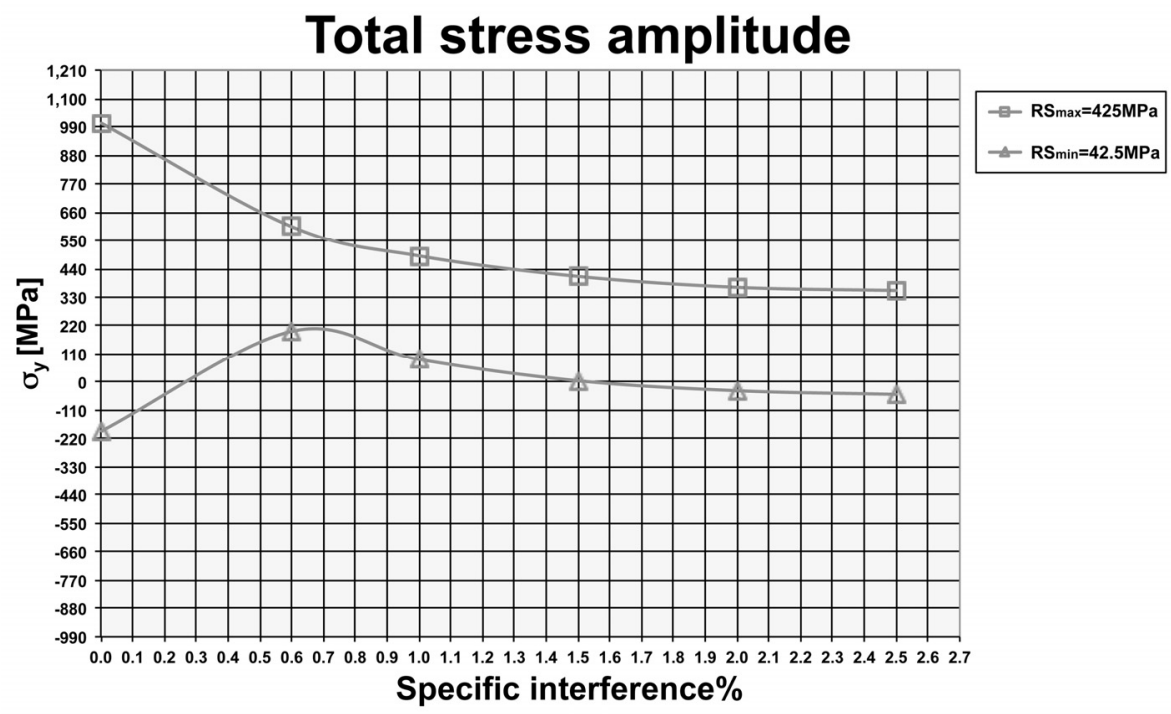

(b)

Figure 7: Stress amplitude diagrams.

\section{CONCLUSIONS}

$\mathrm{I}$ $\mathrm{n}$ this paper the influence of interference fit coupling on the fatigue strength of holed plates has been investigated both experimentally and numerically. The stress-life curves reported in Fig. 4 highlight a significant difference among the open-hole specimen behaviour and the interference-fit ones. The fatigue strength is always higher when the interference level is higher, anyway since the slopes of the interference fit curves are quite different, the increase of fatigue strength is significant when the remote stress is high; on the opposite the Endurance Limit for both the interference fit levels is quit the same. This event depends on the total stress range, which can be reduced by the interference level up to a minimum value depending on the remote stress; therefore it is not advisable to overcome the interference level, which can guarantee the maximum benefit. 


\section{REFERENCES}

[1] D. Croccolo, R. Cuppini, N. Vincenzi, Finite Elements in Analysis and Design, 45(6-7) (2009) 406.

[2] D. Croccolo, M. De Agostinis, N. Vincenzi, Engineering Failure Analysis, 18(1) (2011) 364.

[3] D. Croccolo, M. De Agostinis, N. Vincenzi, International Journal of Adhesion and Adhesives (Special Issue on Joint Design), 30(5) (2010) 359.

[4] D. Croccolo, M. De Agostinis, N. Vincenzi, International Journal of Mechanical Sciences, 56(1) (2012) 77.

[5] D. Croccolo, M. De Agostinis, N. Vincenzi, The Journal of Strain Analysis for Engineering Design, $47(3)$ (2012) 131.

[6] M. Ayatollahi, M. A. Nik, Computational Materials Science, 45(4) (2009) 1134.

[7] T. Chakherlou, Y. Alvandi-Tabrizi, A. Kiani, International Journal of Fatigue, 33(6) (2011) 800.

[8] A. Lanciotti, C. Polese, Fatigue \& Fracture of Engineering Materials \& Structures, 28(7) (2005) 587.

[9] K. Iyer, S. J. Hu, F. L. Brittman, P. C. Wang, D. B. Hayden, S. P. Marin, Fatigue \& Fracture of Engineering Materials \& Structures, 28(11) (2005) 997.

[10] M. Giglio, M. Lodi, International Journal of Fatigue, 31(11-12) (2009) 1978. Fatigue Damage of Structural Materials VII.

[11] T. Chakherlou, M. Mirzajanzadeh, J. Vogwell, Engineering Failure Analysis, 16(7) (2009) 2066.

[12] T.Chakherlou, M. Mirzajanzadeh, B. Abazadeh, K. Saeedi, European Journal of Mechanics - A/Solids, 29(4) (2010) 675.

[13] T. N. Chakherlou, M. Mirzajanzadeh, K. H. Saeedi, Fatigue \& Fracture of Engineering Materials \& Structures, 33(10) (2010) 633. 